\title{
DUST FROM POETRY TO PRACTICE
}

\author{
R.B. Wells \\ Chief Research Office, CSIR, Pretoria, RSA
}

SUMMARY:

The sampling of dusts of all types in the atmosphere is dicussed and the various characteristics which enable dusts to be sorted into various types are discussed. Reference is made to problems associated with impaction sampling and filter sampling.

\section{OPSOMMING:}

Stof, wat in die atmosfeer beweeg is van baie verskillende tipes. Die kenmerke van stofdeeltjies is aangedui en die referaat praat van hulle houding onder skok proewe en in filtreerders.

The place of stacks in pollution control depends on their ability to dilute and disperse two classes of pollutants, namely gaseous pollutants and particulates. For reasons that I will illustrate, the quantitative characterisation of airborne particulates is a difficult but important topic; in the space available only the main principles and a few examples can be given. Detailed treatments can for example be found in the books by Allen ${ }^{1}$, Friedlander ${ }^{2}$ and Shaw ${ }^{3}$.

Our literature has for thousands of years been rich in references to dust in both good and bad contexts. Our genesis was in dust and to that dust we fear to return. Until recently all but the biggest dust particles were too small to be seen individually, instead they made their numbers felt by sheer numbers, they choked Pompeii at the foot of Vesuvius in two days and they sifted slowly down to hide even the pyramids.

A good example of how a qualitative awareness of the properties of dust has seeped into our literature is the poem 'A Peck of Gold by the 20th Century American poet Robert Frost.

\section{A PECK OF GOLD}

Dust always blowing about the town, Except when sea-fog laid it down, And I was one of the children told Some of the blowing dust was gold.

All the dust the wind blew high Appeared like gold in the sunset sky, But I was one of the children told Some of the dust was really gold.

Such was life in the Golden Gate: Gold dusted all we drank and ate, And I was one of the children told, 'We all must eat our peck of gold'.

From our point of view the poem shows some insight into many of the important properties of dust. That the sea-fog laid down the dust brings to our minds the influence of . humidity on the processes of nucleation and coagulation. The question of whether some of the dust was really gold prompts us now to ask, what if some of the dust was really lead or arsenic or any other element: 'All the dust the wind blew high, Appeared like gold in the sunset sky' reminds us of the entrainment of dust by wind and the interesting light scattering properties of dust. 'Gold dusted all we drank and ate' brings us to deposition, the final stage in an airborne pollutant life cycle. Although we may read into Frost's poem more knowledge of dust than he perhaps realised was there, this knowledge is qualitative and is not supported by detailed investigation of dust.

We produce dust from many processes in our techonological civilisation and must now ask ourselves what these dusts really are, and whether they are safe for us and the environment. If they prove to be dangerous how can we trap them or dispose of them? To answer these questions we must equip ourselves with weapons from the armoury of modern techniques. The choice of mothods is critically important, because data from a method inappropriate to the problem it hand may leave us little wiser than the poets of the past. i

We must now move from the ivory tower of the poet to the $300 \mathrm{~m}$ high power station stack and ask ourselves what distinguishes dusts from the materials and objects familiar to us in everyday life. The main difference is the large surface area of finely divided materials. This large surface area means that surface related properties such as evaporation and absorption, solubility, electrostatic activity and catalytic activity become more important than bulk properties. To see how surface area increases with subdivision consider a sphere of volume $1 \mathrm{~cm}^{3}$ and surface area $0,00048 \mathrm{~m}^{2}$. If this sphere is subdivided to yield spheres of diameter $0,124 \mu \mathrm{m}$ the surface area increases to $48 \mathrm{~m}^{2}$ i.e. 5 orders of magnitude. Surface properties that are imperceptible for a marble dominate the behaviour of a dust.

I cannot here go into the subtleties of the science of particle identification ${ }^{4}$ using optical and electron microscopy. For my present purpose the useful spin-off of the published literature on particle identification is that it reveals the amazing diversity of form and composition present in the materials which we casually lump together as dust. Even a dust which is chemically uniform may be physically so irregular that no two particles are the same. How are we to mathematically describe such a mateiral, let alone predict its behaviour? Consider an analogy to this problem in everyday life. Mount Everest is 2,7 times as high as Mont-auxSources, therefore we could state that Mount Everest will be 2,7 times as difficult to climb as Mont-aux-Sources. 
Even non-mountaineers will realise that this extrapolation is not valid, height alone is not an adequate measure of the difficulty of climbing an irregular object such as a mountain.

Many different physical parameters can be used to define the size of a particle to some extent. Some of these parameters are: mass, volume, surface area, and diameters of various sorts. Allen lists twelve diameters among which are:

\begin{tabular}{|c|c|c|}
\hline Symbol & Name & Definition \\
\hline$d_{v}$ & $\begin{array}{l}\text { Volume } \\
\text { diameter }\end{array}$ & $\begin{array}{l}\text { Diameter of a sphere having the } \\
\text { same volume as the particle }\end{array}$ \\
\hline $\mathrm{d}_{\mathrm{s}}$ & $\begin{array}{l}\text { Surface } \\
\text { diameter }\end{array}$ & $\begin{array}{l}\text { Diameter of a sphere having the } \\
\text { same surface as the particle }\end{array}$ \\
\hline $\mathrm{d}_{\text {st }}$ & $\begin{array}{l}\text { Stokes' } \\
\text { diameter }\end{array}$ & $\begin{array}{l}\text { The free-falling diameter of a } \\
\text { particle in the laminar flow regio }\end{array}$ \\
\hline $\mathrm{d}_{\mathrm{a}}$ & $\begin{array}{l}\text { Projected } \\
\text { area } \\
\text { diameter }\end{array}$ & $\begin{array}{l}\text { Diameter of a circle having the } \\
\text { same area as the projected area } \\
\text { of the particle resting in a stable } \\
\text { position }\end{array}$ \\
\hline $\mathrm{d}_{\mathrm{A}}$ & $\begin{array}{l}\text { Sieve } \\
\text { diameter }\end{array}$ & $\begin{array}{l}\text { The width of the minimum } \\
\text { square aperture through which } \\
\text { the particle will pass }\end{array}$ \\
\hline
\end{tabular}

Note that most of these are equivalent diameters by means of which we try to describe the irregular particle in terms of a sphere which will show the same behaviour under specified test conditions. When choosing a size parameter one must decide what it is that one needs to know about a dust sample. This usually boils down to wanting to understand or predict the behaviour of a dust in some real life situation. Typical subjects might be:

a) Dust transport in a duct or stack

b) Dust deposition and clearance in the lung

c) Behaviour of dust in an electrostatic precipitator

d) Catalytic effect of dust on $\mathrm{SO}_{2}$ oxidation in a plume

e) Visual disfigurement of building by dust

In each case one or more properties is of prime importance, thus for the above examples the most useful parameters are:

a) Aerodynamic diameter

b) Aerodynamic diameter

c) Aerodynamic diameter and conductivity

d) Surface area and chemical composition

e) Projected surface area and colour
Many of the parameters used to define the sizes of irregular particles are operational in nature, that is they depend on the instrument used to examine the dust and the dust is described in terms of its behaviour in that instrument. The correct choice of size parameter and measuring instrument often results in the instrument creating an idealised simplification of the problem.

An example of a device that reproduces in idealised fashion the processes of impaction that can occur in industrial equipment or in the human-being is the cascade impactor, two stages of which are illustrated in Figure 1. Each stage has a hole through which the aerosol passes to form a jet of air which hits a collecting plate. As the air jet hits the plate it makes an abrupt change in direction. Depending on the relation between the aerodynamic drag and the inertia of a particle it will either follow the air motion or hit the collecting plate where it will be deposited. Successive stages have smaller holes, faster air jets and deposit correspondingly smaller dust particles. Ideally each stage would have $100 \%$ efficiency and collect all particles larger than a given size. In practice the air velocity in the jet will not be uniform nor will all parts of the jet make an identical change of direction. In addition collision with the collector plate may not ensure that a particle remains on the plate, rebound or re-entrainment may occur. Thus the efficiency of a stage is less than $100 \%$ and is defined as the fraction of particles of a given size which are collected by the stage from the passing aerosol. Figure 2 shows schematically the typically $\mathrm{S}$ shaped relationship between efficiency and aerodynamic diameter. Each stage is characterised by the aerodynamic diameter at which the collection efficiency is $50 \%$. Collection

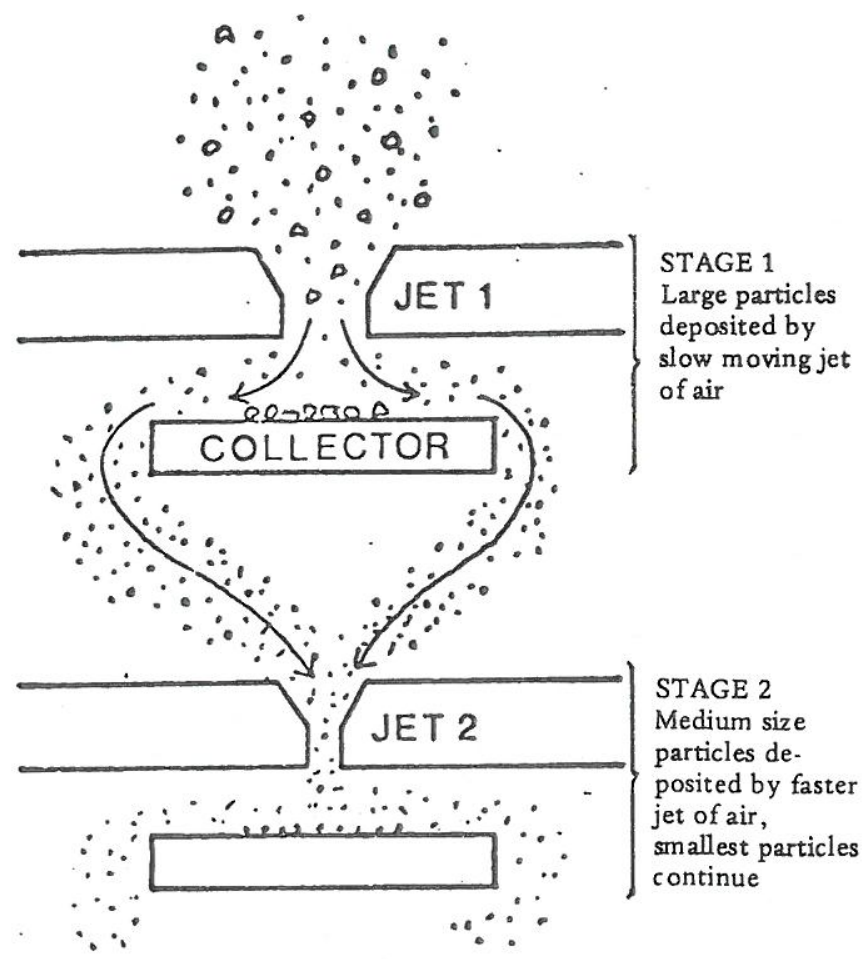




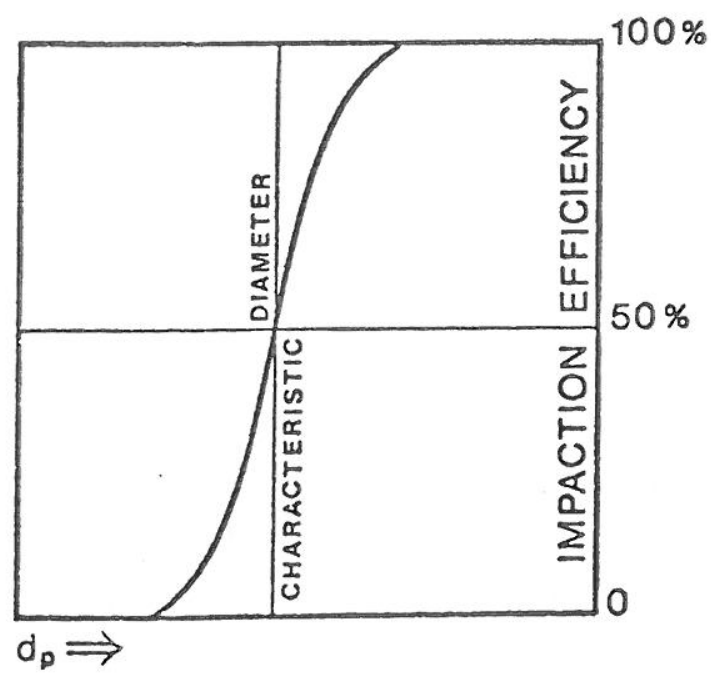

FIGURE 2

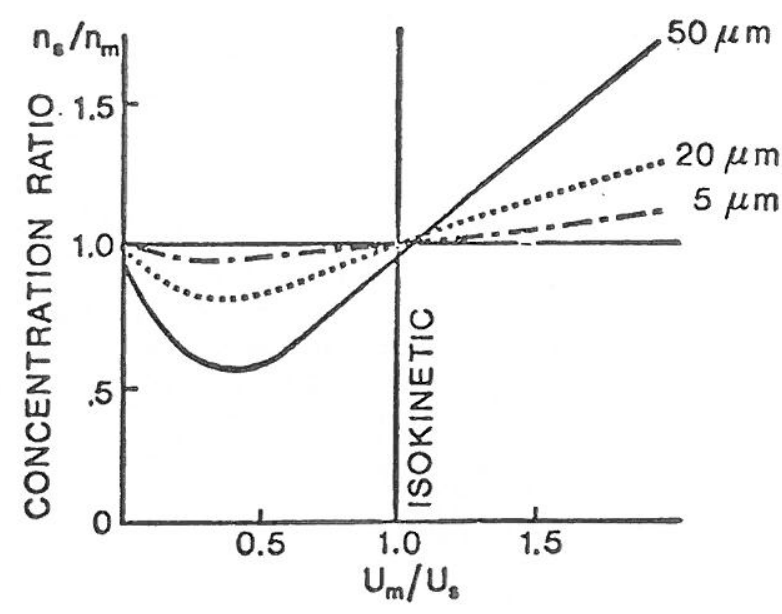

FIGURE 3
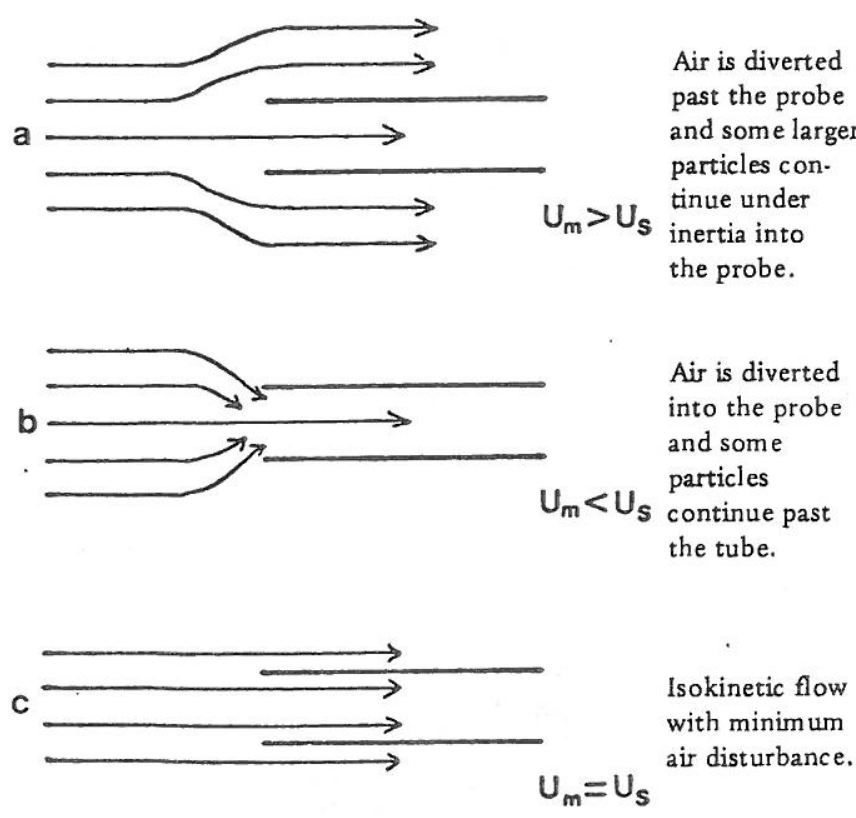

FIGURE 4 efficiency curves are determined experimentally using mono-disperse spherical aerosols but this situation is unlikely to occur in practice. Even if a stage had a perfect collection efficiency, microscopic examination of a stage exposed to a real atmospheric aerosol would show particles with a great variety of sizes, shapes and densities. The only common factor is that under the conditions of that impactor all the particles showed the same overall aerodynamic behaviour which caused them to be collected. The particles are said to have the same aerodynamic diameter, that is the diameter of a sphere of unit density with the same settling velocity. A typical impactor may have about 8 stages and can resolve an aerosol into size fractions between perhaps 0,1 and $10 \mu \mathrm{m}$. Having collected the sample of dust on each stage it may
a) be weighed
b) analysed e.g. PIXE
c) examined by electron or optical microscope

A modification of the cascade impactor uses piezo-electric crystals as the collecting surface, the change in vibrational frequency as dust is collected gives a continuous record of the mass of dust in each size range.

The principle of inertial impaction used in the cascade impactor suggests that wherever dust laden air is accelerated or deflected we must expect to find segregation of the dust particles according to size. For small particles it will be easy to achieve and maintain a homogenous aerosol but for larger particles segregation will occur. This means that no matter how we sample and analyse we will always have to take care to obtain a representative sample at each sampling point and to ensure that the sampling points adequately represent the volume of space to be investigated. Thisproblem is very well known for the sampling of dust from ducts and stacks by means of a probe oriented in the direction of gas flow. If $n_{s}$ is the dust concentration in the sample which is drawn into the probe with velocity $u_{s}$ and $n_{m}$ is the concentration in the mainstream moving with velocity $U_{m}$ then Figure 3 shows how $n_{s} / N_{m}$ depend on $U_{m} / U_{s}$ for particles of varying aerodynamic diameters. If $U_{m}>U_{s}$ as in Figure 4(a) then the flow lines will be deflected round the probe and some heavier particles will fail to follow the air movement and will enter the probe. Alternatively, if $U_{m}<U_{s}$ Figure 4 (b) the flow will be into he probe but not all particles will manage to follow the flow lines. Except for small particles with $d_{p}<5 \mu \mathrm{m}$ the only satisfactory case is if $\mathrm{U}_{\mathrm{m}} / \mathrm{U}_{\mathrm{s}}=1$ i.e. the isokinetic state shown in Figure 4 (c).

The cascade impactor is merely one of many instruments for measuring various size parameters. What seems to me important is that it is a good example of an instrument which simplifies an important process and gives us useable information on dusts that are so irregular as to defy discription.

The effort spent on particle 'size' measurement is justified by the fact that many dust properties are strongly size' dependant. The examples below illustrate this point. Figure 5 shows the collection efficiency of a fibrous filter as a 


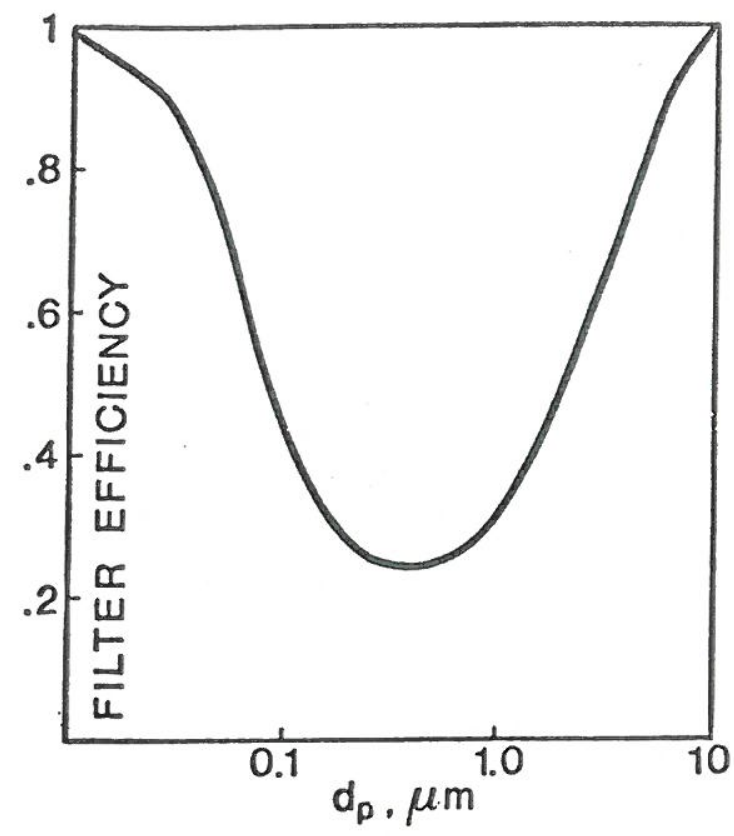

FIGURE 5

function of particle size. In such cases the particles are usually experimentally produced spherical monodisperse aerosols. For particles larger than $1 \mu \mathrm{m}$ the main removal mechanism is inertial deposition on the filter fibres and efficiency increases with size. For particles smaller than $0,1 \mu \mathrm{m}$ efficiency increases with decreasing size. The mean free path of molecules in air is about $0,065 \mu \mathrm{m}$ and when dust particles are this size or smaller, they undergo Brownian movement, their motion is controlled by random collisions with individual gas molecules. Thus particles smaller than $0,1 \mu \mathrm{m}$ can reach the filter fibres by a process of diffusion that becomes faster with decreasing particle size. The resultant collection efficeincy from the two processes of particle removal shows a minimum between 0,1 and $1 \mu \mathrm{m}$, corresponding to the transition between diffusional and inertial deposition. Variable factors such as the air velocity through the filter and the fibre diameter will affect the efficiency curve but the form shown in Figure 5 is very general.

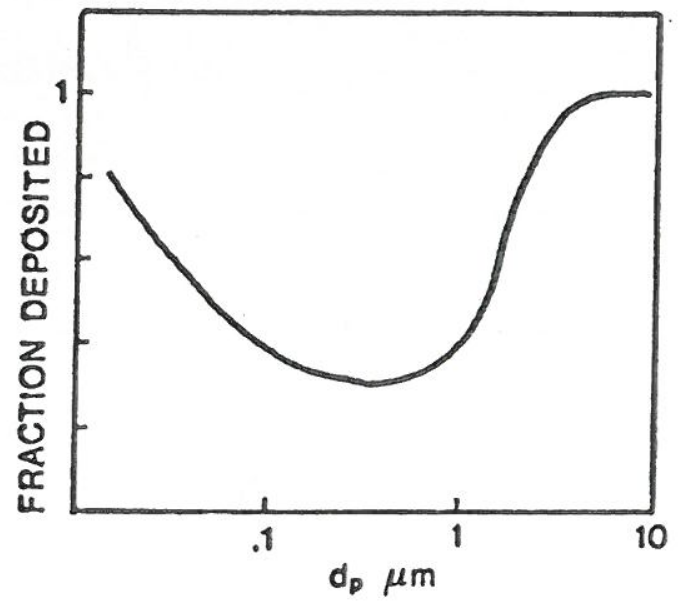

FIGURE 6

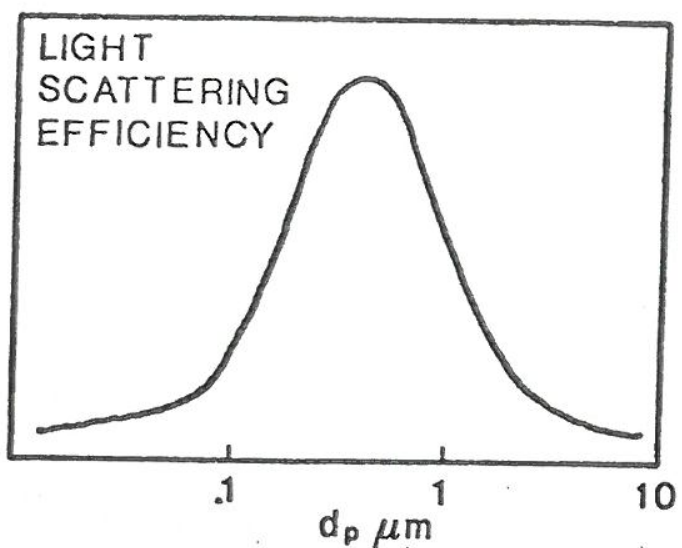

FIGURE 7

The human-being also has an efficiency curve for particle deposition that has a minimum between a diameter of 0,1 and $1 \mu \mathrm{m}$, Figure 6 . For particles smaller than $0,1 \mu \mathrm{m}$ deposition is mainly by diffusion. Particles larger than $1 \mu \mathrm{m}$ are mainly deposited by inertial impaction and sedimentation under gravity.

The poem. by Frost states in a qualitative way that dust scatters light, Figure 7 shows in more quantitative fashion that the efficiency of light scattering depends strongly on size. In this case there is a strong maximum in scattering efficiency between 0,1 and $1 \mu \mathrm{m}$. Visual pollution will be greatest by particles with diameters between 0,1 $-1 \mu \mathrm{m}$.

One of the most important ways of removing dust from stack gases is the electrostatic precipitator, Figure 8 shows how for a given case collection efficiency depends on particle size. It is unfortunate that the collection reaches a minimum at the particle size $(0,1-1 \mu \mathrm{m})$ which we just previously saw has the highest light scattering efficiency. This minimum in collection efficiency is thought to result from a transition between diffusion charging for small particles and field changing of larger particles.

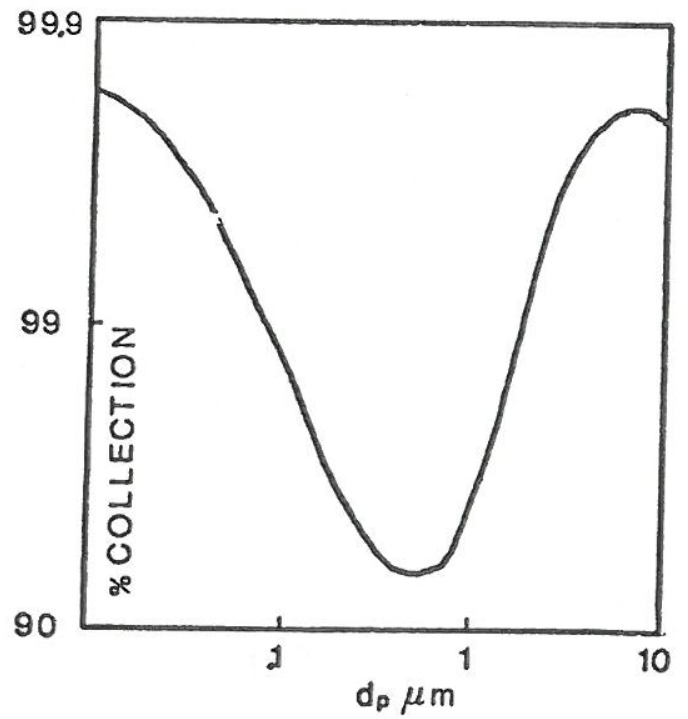

FIGURE 8 